\title{
The Effects of Role Stressors, Work-Related Hassles, and Critical Job Events on Mental Health over Time: A Study of New Employees
}

\author{
Meyrav Marom ${ }^{1} \&$ Meni Koslowsky ${ }^{2}$ \\ ${ }^{1}$ The David Yellin Academic College of Education, Jerusalem, Israel \\ ${ }^{2}$ Bar-Ilan University, Ramat-Gan, Israel \\ Correspondences: Meyrav Marom, The David Yellin Academic College of Education, 7 Maagal Beit Hamidrash \\ St., P.O. Box 3578, Jerusalem 9103501, Israel. E-mail: eli159@bezeqint.net
}

\author{
Received: May 15, 2013 Accepted: July 8, $2013 \quad$ Online Published: August 15, 2013 \\ doi:10.5539/ijps.v5n3p108 URL: http://dx.doi.org/10.5539/ijps.v5n3p108
}

\begin{abstract}
This study examined the differential and mediating effects of three types of work-related stressors: critical events, hassles and role stressors - on nurses' levels of distress at two points in time during their first hospital-based job. Role stressors were hypothesized to fully mediate the effects of hassles and partially mediate the effects of critical events on distress at both Time 1 and Time 2. We also hypothesized that critical events and role stressors, as well as role stressors and distress, would reciprocally influence each other across time. The findings provided full support for the first expectation and partial support for the second. The current study is the first to clarify the nature of the relationships among the three types of stressors, thus adding to our theoretical reasoning concerning their interrelationships and clarifying for practitioners the critically important types of stressors in terms of their effects on aspects of mental health.
\end{abstract}

Keywords: role stressors, work-related hassles, critical, job events, mental health, new employees

\section{Introduction}

There has been ongoing interest in the relationships among the major types of work-related stressors as they impact employee well-being (Koslowsky, 1998) and job performance (Gilboa, Shirom, Fried, \& Cooper, 2008). In order to understand the effects of work-related stressors on psychological distress, referred to as distress below, it is necessary to understand how major types of stressors, including critical job-related events, daily work-related hassles, and role stressors, relate to each other and how they affect distress. We are not aware of any previous study that has followed this route using a longitudinal design. The current study responds to this lack by being the first to investigate critical job events, daily hassles, and role stressors as they relate to distress, across time. Past studies compared pairs of stressor types, such as critical events and hassles or hassles and role stressors, as they influenced aspects of mental health, often based on a cross-sectional design. Our objective is to contribute to the theory of the interrelationships among different types of stressors across time with each other and with distress, a critical aspect of mental health. As further explained below, using all three major types of stressors across time has the major theoretical advantage of representing in a single study the major dimensions underlying most stressors in a workplace. We used the three types of stressors regarded by previous research as the most influential in terms of their effects on performance and mental health in the context of work (Hart \& Cooper, 2002; Wheaton, 1994) and therefore, the most heavily investigated heretofore.

\subsection{The Study Context}

We investigated changes in role stressors, work-related hassles, and critical job-related events as perceived during an employee's first months of work in an organization. There are several reasons for the focus on novice employees. First, high levels of perceived stress usually characterize the first few months on a new job, because employees are required to learn new tasks and adapt to new demands while maintaining acceptable levels of performance (Saks \& Ashforth, 2000). Second, studying a cohort of new entrants in an organization controls to a large extent for the potential confounders of organizational tenure and level; both of which tend to be associated with coping resources, such as support systems, control, and predictability of stressful demands (Shirom, Shechter-Gilboa, Fried, \& Cooper, 2008). Study participants included degreed hospital nurses in their initial months of work. As novice nurses have been shown to report high levels of stress at work relative to veteran 
nurses (Gelsema, van der Doef, Maes, Akerboom, \& Verhoeven, 2005), they provide a naturalistic setting for studying the influence across time of several types of stressors on a key aspect of nurses' mental health, their levels of distress.

Distress was conceptualized, following Veit and Ware (1983), as consisting of symptoms of depression, anxiety, and loss of control. Most approaches to work-related stressors agree that it is associated with threatening or harmful demands as perceived by employees (Beehr, 1998). As noted, the three types of stressors commonly discussed in the literature are role stressors, work-related hassles, and critical job events - all were contextualized in this study to refer primarily to the domain of work to make them comparable. Therefore, we refer to these stressors in the current study as "critical job events" and as "work-related hassles". We focus on the three types of stressors that have been most often used in studies of work-related stressors (Ortqvist \& Wincent, 2006). They are differentiated according to three major theoretical dimensions underlying the realm of stress in places of employment: duration, intensity, and frequency of the demand addressed to an individual (Wheaton, 1994). Critical job events have a short duration, low frequency and high intensity; for example, being severely reprimanded by one's superior. Critical job events as a type of stressor stems from the medical model of stress that views the mere occurrence of an event as demanding adaptation, thus depleting an individual's adaptive resources (Hammen, 2005). Hassles are similar to critical life events, except that they are much less intense and occur frequently in most people's daily work lives; for example, missing the bus while commuting to work. In other words, hassles represent relatively minor stressors that characterize everyday life at work (Kanner, Coyne, Schaefer, \& Lazarus, 1981). A role stressor, such as continuous work overload, has a long duration and medium to high intensity. In the current study, a role stressor has been conceptualized in terms of one's role because people organize their daily activities in terms of role boundaries (Wheaton, 1997). The focus is on three types of role stressors that were found in a recent meta-analytic study to be those most often used in studying role performance (Gilboa, Shirom, Fried, \& Cooper, 2008): role ambiguity (lack of clear and predictable demands), role conflict (irreconcilable demands), and role overload (demands for too much work in too little time). While there are some claims that moderate levels of role stressors at work may be conducive to creativity and vitality, the most recent meta-analytic study (Gilboa et al., 2008) found no evidence supporting this contention

\subsection{The Theoretical Model}

In a review of temporal issues in organizational behavior, Mitchell and James (2001) argued that most theory in this area does not consider the temporal dimension including such key questions as when an effect is likely to occur and for what duration. We based our hypotheses on this perspective. Several models of organizational socialization view the very first months of work in an organization as characterized by a phenomenon referred to as 'role shock' (Ashforth, Sluss, \& Saks, 2007). Role shock refers to the well-documented finding that during this period, employees are required to learn new tasks, define their relationships with significant others in the work environment, and learn how to perform their new role effectively. As argued by several theories of the organizational entry process (Ashforth, 2001), after spending some time in a new job, a newcomer becomes more habituated to the positive qualities of the job, including its support networks, than to its negative aspects. After gaining some experience in the new job, newcomers view its positive aspects as normal. Regardless of the learning process accompanying repeated exposure to job-related demands, these positive qualities tend to be regarded as an employee right. Therefore, it is argued that as the entry process unfolds, newcomers begin to regard the negative aspects of their job as more salient (Ashforth, 2001). Research on information processing indicates that people tend to react more strongly to negative rather than positive information (Baumeister, Bratslavsky, Finkenauer, \& Vohs, 2001). Based on the above theoretical arguments, we expected that over time, the more frequent stressor would be more proximate to a person's daily work activities. Role stressors are the most frequent stressor and have the longest duration (Ortqvist \& Wincent, 2006). Therefore, we regarded role stressors as the type of stressor predicting distress. In addition, the theoretical assumption that role stressors are the most proximal to a person increases the likelihood that they will mediate the effects of the other types of stressors, critical job events and work-related hassles, on distress across time. Below, we summarize the results of past research, albeit largely based on a cross-sectional design, supporting the above theoretical arguments.

\subsection{Major Hypotheses Concerning Longitudinal Relationships}

We refer to the two waves of measurement in the current study as Time 1 (T1) and Time 2 (T2). In Figure 1, each arrow depicts a possible specific study hypothesis. Based on the theoretical arguments explained above, our focus was on the hypotheses that involve changes across time rather than on cross-sectional relationships among the three types of stressors and distress. Therefore, the arrows relevant to the present study are those relating T2 types of stressors to $\mathrm{T} 2$ distress while controlling for $\mathrm{T} 1$ levels of the variables connected by the arrows. Therefore, the study included the arrows in Figure 1 that lead from T2 critical job events to T2 work-related 
hassles, to T2 role stressors and to T2 distress. To test our hypotheses, we used structural equation modeling (SEM; Kline, 2011). In addition to its other major advantages, such as controlling for measurement errors, SEM allowed us to use a comprehensive test of all our major hypotheses in terms of their overall fit with the data (Kline, 2011). In considering the effects at T2, we controlled for the T1 level of the same variable, represented by the horizontal arrows in Figure 1, because it allowed us to regard all T2 variables as changes across time between T1 and T2 (Twisk, 2003; Kline, 2011).

We argue that this is one of the first studies to simultaneously examine the effects of the three types of stressors on mental health using a longitudinal design. A possible exception is a study that used the three types of stressors to predict mental health (Eckenrode, 1984). However, Eckenrode (1984) used low income and low education both representing objective stressors - to assess role stressors, and assessed hassles as responses to an open-ended question "Did anything go wrong today?", - a measure of hassles, which is largely inconsistent with the measure of other hassles and its validity is questionable. The other study (Wheaton 1994) is not comparable with our model because - in addition to the three types of stressors under study - it also examined childhood traumas, desired events that had not materialized in the past year, and earlier adulthood life events. In reviewing relevant past studies, we excluded those that were based on pre- or post-employment individuals as participants, on participants diagnosed as having a role disease, or studies that examined traumatic events (e.g., Brough, 2004) because of their rarity and their association with a specific post-traumatic stress response.

We expected T2 role stressors to predict T2 distress directly, again after controlling for their T1 levels. We proposed that $\mathrm{T} 2$ hassles, less proximate to the individual than role stressors, but still more frequent and less distal than T2 critical job events, would mediate the effects of T2 critical job events on T2 role stressors and T2 distress. We expected $\mathrm{T} 2$ critical job events to have a direct effect on $\mathrm{T} 2$ distress in addition to their impact on $\mathrm{T} 2$ hassles. Below, we present theoretical arguments and a summary of past research for each of these paths.

T2 critical job events predict T2 work-related hassles (Hypothesis 1) and T2 critical job events predict T2 distress (Hypothesis 2). Hassles have been viewed as reflecting to some extent the effects of critical job events (Kanner, Coyne, Schaefer, \& Lazarus, 1981). A critical job event, for example a demotion, might give rise to a variety of work-related hassles, such as having to arrive earlier at work. A critical job event may also change the extent to which preexisting work-related hassles are perceived as threatening (Wagner, 1990). Following this rationale and past research, we expected $\mathrm{T} 2$ critical job events to predict $\mathrm{T} 2$ work-related hassles.

We expected T2 critical job events to have a direct effect on T2 distress over and above its effect on T2 work-related hassles, for the following reasons. As we posited above, a body of theory and research on critical events, based on the theoretical idea of the "kindling hypothesis" (Hammen, 2005; Monroe, Slavick, Gotblib \& Torres, 2007; Monroe \& Harkness, 2005) supports the assumption that critical job events and work-related hassles are directly related to T2 distress, because critical events and changes in their occurrence over time make the employee more vulnerable to experiencing distress (Dohrenwend, 2006). The "kindling hypothesis" (Monroe et al., 2007, 2005; Dohrenwend, 2006) suggests that the mechanism explaining the effects of critical events on distress may involve other less intense types of stressors, including hassles and role stressors. A body of evidence supports the mediation of the effect of critical events on distress by hassles (Aldwin, 2007, p. 77-78). For example, several studies (Pillow, Zautra, \& Sandler, 1996; Wagner, 1990) found that the effects of critical job events on aspects of mental health are mediated by hassles. Following this evidence, we hypothesized that hassles would mediate the prediction of $\mathrm{T} 2$ distress caused by $\mathrm{T} 2$ critical job events.

Critical job events require people to make adjustments in their daily life, some of which might tax their coping abilities, thereby making them more vulnerable to distress (Dohrenwend, 2006). Additionally, the higher the exposure to critical job events, the higher the risk of losing coping resources and the higher a person's stress reactivity (Dohrenwend, 2006). Accumulated evidence strongly supports the direct effect of critical job events on different aspects of mental health, including depression and anxiety (Heim \& Nemeroff, 2001). There is evidence that critical job events at work continue to impact mental health even after the effects of role stressors are controlled for (Glickman, Tanaka, \& Chan, 1991).

T2 work-related hassles predict T2 role stressors (Hypothesis 3). The accumulation of small negative events at work can build up over time to create continuous role stressors, and may disrupt individuals' adjustment processes, hence increasing their levels of role stressors (Hart \& Cooper, 2002). Because role stressors reflect ongoing and continuous stressors, while work-related hassles are conceptualized as having a short duration and low intensity, we argue that role stressors should absorb the cumulative adaptation needs represented by work-related hassles. For example, missing a bus while commuting to work is a hassle, but it may be directly reflected in higher levels of workload because of one's lateness behavior. There is some support for this 
theoretical argument (Serido, Almeida, \& Wethington, 2004). Additionally, role stressors cause a continuous, persistent depletion of an individual's coping resources. Therefore, they are likely to fully reflect the effects of work-related hassles (Lepore \& Evans, 1996).

Previous studies that compared hassles and role stressors as predictors of distress did not provide conclusive evidence of their relationships, but provided strong support for the unique contribution of each in predicting distress (for a review, see Serido et al., 2004). Several studies support the hypothesis that the effects of hassles on distress are mediated by role stressors (Lepore \& Evans, 1996; van Eck, Nicolson, \& Berkhof, 1998).

T2 role stressors predict T2 distress (Hypothesis 4). As suggested by Lazarus and Folkman (1984, p. 231), role stressors represent proximal forms of stressors likely to be manifested in the immediate context of an individual's thoughts, feelings, and actions. Furthermore, accumulated evidence supports the notion that the human body is better programmed to cope with infrequent but intense stressors, like the need to flee from danger and is less prepared to cope with frequently appearing, persistent role stressors (Hart \& Cooper, 2002). Hammen (2005) provided a recent review of this body of studies. Therefore, we expected a direct prediction of T2 distress by $\mathrm{T} 2$ role stressors.

\subsection{Alternative Models}

It is highly recommended that researchers using SEM to test their hypotheses develop several alternative theoretical models and compare each of them with the hypothesized theoretical framework (Kline, 2011). In fact, this is a major advantage of SEM, being able to compare the fit with the data of many alternative theoretical frameworks involving the same set of variables (Kline, 2011). Therefore, we systematically tested alternative models to the one posited above. The first alternative model that we tested posits that $\mathrm{T} 2$ role stressors only mediate the effects of T2 hassles on T2 distress (as argued, for example, by van Eck et al., 1998). That is, this alternative model expects a direct path between $\mathrm{T} 2$ work-related hassles and $\mathrm{T} 2$ distress in addition to the direct effect of T2 hassles on T2 role stressors. There is some support for this alternative model in a longitudinal study (Holahan, Moos, Holahan, Brennan, \& Schutte, 2005).

We tested several additional alternative models, on an exploratory basis. We tested the possibility that there are reciprocal relationships across time between $\mathrm{T} 1$ critical job events and $\mathrm{T} 2$ role stressors (described as path $\mathrm{A}$ in Figure 1), between T1 role stressors and T2 distress (see path B in Figure 1), between T1 role stressors and T2 critical job events (path $\mathrm{C}$ in Figure 1) and between T1 distress and T2 role stressors (path D in Figure 1). Below, we report the results of these exploratory analyses.

\section{Method}

\subsection{Participants}

The present study used a two-wave longitudinal design and included all new nurses who were employed in publicly owned, 25 acute-care non-profit hospitals in Israel. In 2008, there were 47 acute-care hospitals in the country (State of Israel, 2010). In the sampling frame, we did not include 17 small hospitals with less than 100 beds each, mostly operated by religious charities in peripheral areas of the country. Of the remaining 30 hospitals, eleven were government hospitals (representing about $37 \%$ of the acute-care beds), eight were owned and operated by the General Health Services Fund, and the rest were owned and operated by other public organizations (for example, the Hadassah Hospitals in Jerusalem). Of the remaining 30 acute-care public hospitals, 25 agreed to participate in the study and constituted our sample.

The Time 1 (T1) questionnaire was sent by mail to 324 nurses who appeared on the hospitals' employee rosters and who had joined the staff during the five months prior to the study. From this group, 234 questionnaires were returned, a response rate of $72 \%$. At Time 2 (T2), the study questionnaire was sent to all those who responded to the T1 questionnaire, of whom 201 responded and made up the study sample. This response rate, approximately $60 \%$, is considered quite satisfactory (Baruch \& Holtom, 2008). The nurses were employed primarily in the internal medicine (18\%), surgical (17\%), intensive care (17\%), and pediatric $(9 \%)$ wards.

In order to examine whether a systematic $\mathrm{T} 1$ to $\mathrm{T} 2$ attrition occurred, analyses were conducted to examine the significance of the difference in the study variables between subjects who responded to both T1 and T2 questionnaires, and those who responded only at T1. Except a significant difference on the measure of occupational attainment, no significant difference was found between the two groups on either variable. Because we tested 20 different variables ${ }^{1}$, this difference can be explained as a chance result. We concluded that there was no systematic bias due to the attrition. The final sample's respondents comprised mostly females $(90 \%)$ with a mean age of 27.4 years. About $5 \%$ of the subjects were nurse practitioners, $57 \%$ were registered nurses, and $32 \%$ were registered nurses who also had an academic degree in nursing. Among the respondents, $63 \%$ had no 
children; and $75 \%$ were nurses new to the profession, with less than one year of tenure. Finally, $54 \%$ were born in Israel, with the rest coming from countries worldwide. On the average, 6 months separated T1 and T2 waves of data collection; we based this time interval on the socialization literature viewing the first year on a new job as a critical period for adjustment and socialization to a new nursing job (Saks \& Ashforth, 2000).

\subsection{Measures}

A measure of internal consistency (Cronbach's alpha) was used to assess the reliability of each multi-item indicator of the latent factors included in the current study.

Hassles: The Hassles questionnaire consisted of ten items, all describing work-related hassles, taken from the Hassle Questionnaire developed by Kanner and associates (1981). These items were carefully selected to reduce the likelihood that they were contaminated by distress or other types of stressors and to be appropriate for beginning nurses, in accordance with the recommendation of Wheaton (1994, 1997). Respondents were requested to indicate the frequency of each event over the previous month. The scale ranged from 1 (very infrequent) to 5 (very frequent). Regarding the latent variable representing hassles, they were allocated into three parcels, denoted by P1, P2, and P3 in Figure 2. P1 included three items reflecting commuting hassles ("You had an uncomfortable drive in the bus or car while commuting to work"), with $\alpha=.73$ and .75 at T1 and T2, respectively. P2 included four items primarily having to do with interpersonal hassles ("You had a minor argument with the head nurse"), with $\alpha=.76$ and .73 at T1 and T2, respectively. P3 included three items dealing with minor irritations at work ("You had to complete a long form at work"), with $\alpha=.70$ and .71 at T1 and T2, respectively.

Role Stressors: To measure role conflict and ambiguity, we used the Rizzo et al. (Rizzo, House, \& Lirtzman, 1970) scales, frequently used in the stress literature and with acceptable validity, including in Israel. The role conflict scale included 6 items and the role ambiguity scale 5 items, with $\alpha=.70$ and .75 at T1 and .80 and .83 at T2. The role overload scale included 5 items based on the Nursing Stress Scale (Gray-Toft \& Anderson, 1981), with $\alpha=.85$ and .83 at T1 and T2, respectively. Respondents were asked to indicate to what extent each of these items usually exists in their job.

Critical job events: The critical job events scale included ten work-related items adapted from the critical life events scale constructed and validated by Levav and colleagues (Levav, Krasnoff, \& Dohrenwend, 1981) and included only negative items. Items from the above critical life events scale that were confounded with hassles were screened and eliminated. We used items only if they were clearly work-related or job focused. Subjects were asked to indicate the number of times in the past six months that they had experienced each of the ten events on the list. Following Crandall (1992), we used an additive model and the total score on this scale was based on the number of items indicated as experienced by a participant. Many previous studies of life events use a similar approach (e.g., Eckenrode, 1984). Examples of items are "You made a severe mistake at work" and "You were strongly reprimanded by your head nurse." The reliability measures were above 0.65.

Distress: The measure of distress was derived from the Mental Health Inventory (MHI), developed by Veit and Ware (1983). The MHI consists of three subscales: depression, anxiety, and loss of control, assessed by 22 items (for example, "I felt anxious"; "I was in a depressed mood"; "I felt lonely"). This measure was validated in Hebrew (Florian \& Drory, 1990) and has been used frequently to gauge psychological distress (see Florian \& Drory, 1990, for a review of studies using the MHI). Florian and Drory (1990) confirmed the three-factor structure of the distress measure in their validation studies. The reliability measures in both time waves were above 0.95 .

Instrumental variables. Following the general recommendations in the structural equation modeling (SEM) literature (Antonakis, Bendahan, Jacquart, \& Lalive, 2010; Foster \& McLanahan, 1996), we used three instrumental variables to ensure identification of the hypothesized paths in our model: number of children for T1 critical job events, age for T1 hassles, and the personality predisposition of challenge for role stressors. The choice of the instrumental variables was based on the considerations detailed by Antonakis and his colleagues, including the fact that each instrumental variable preceded our T1 wave of measurement and was found to be related to one and only one of our T1 types of stressors and distress (Antonakis et al., 2010). There is evidence of age differences in individuals reporting work-related hassles (Neupert, Almeida, \& Charles, 2007). Number of children and age were used as reported by the participants in the T1 questionnaire. The measure of challenge, one of the three facets of the hardiness construct proposed by Kobasa as a personality predisposition (Kobasa \& Pucetti, 1983) was validated in Hebrew (Kravetz, Drory, \& Florian, 1993). It consists of 17 items assessed on a scale ranging from 1 (not at all true) to 5 (completely true). Sample items are: "I like diversity in my work" and "I enjoy being with people whose behavior is unpredictable" $(\alpha=.93)$. We used challenge as an observed 
variable in the SEM analysis, indicated by its mean value.

\subsection{Procedure}

The study was approved by the Helsinki Committee of Bar Ilan University. We mailed the T1 questionnaires to each nurse who had started working during the previous five months. The importance of the study was explained and full confidentiality was assured. The accompanying letter emphasized that the study was for research purposes and was unrelated to their workplace, pledging that no one in the hospital would see the completed questionnaires. In addition, respondents to both questionnaires were paid the equivalent of $\$ 20$ in local currency. Providing payment is known as an efficient method of increasing response rates (Church, 1993). Two versions of the questionnaire were randomly sent to the participants; in each version, the sub-questions were arranged in a different order to prevent primacy or order effects. The T2 measurement was performed six months after T1.

\subsection{Analytic Methods}

Data analysis was performed mainly with SEM (structural equation modeling), using AMOS software. Because of the few missing cases, we used the Full Information Maximum Likelihood (FIML) procedure available in AMOS FIML (Arbuckle \& Wothke, 1999).

To assess the goodness of fit of each of our models with the data, we used two approximate fit indices, the Tucker-Lewis index (TLI: also known as the non-normed fit index) and the comparative fit index (CFI). We also used two misfit indices. The first is the root mean square error of approximation index (RMSEA), with its $90 \%$ confidence interval. The second misfit index is the standardized root mean square residuals index (SRMR), a statistic related to the correlations' residuals. For a description of each index used, see Kline (2011, pp. 204-209). The above four indices of approximate fit and misfit are among those highly recommended in the SEM literature (O'Boyle \& Williams, 2011). We used parcels to represent the indicators of hassles because this analytic method corrects for the non-normal distributions of some items gauging hassles in the current study (Little, Cunningham, Shahar, \& Widaman, 2002; Williams \& O'Boyle, 2008).

The model examined in AMOS was suggested by the research hypotheses. The analysis was performed simultaneously for both time points, to test our hypotheses. We compared alternative models using the $\chi^{2}$ difference test.

As required in estimating longitudinal models, the models included the correlations between the T1 and T2 errors of the same indicator of each type of stressors and distress. No other correlated errors were included in the model. We first assessed the measurement model of each latent factor. We then assessed the factorial invariance, which indicates the extent to which the loadings of the indicators of each latent factor remained invariant across the two waves. Subsequently, we assessed the adequacy of the measurement model of each of the latent factors included in our analyses as well as of the full structural model (Figure 1). We found strong support for our assumption that each type of stressor included in the study was unique. We found this support in a series of confirmatory factor analyses (CFA) conducted prior to testing the major hypotheses. In these CFA, we systematically compared, for each of the three types of stressors in our study, a CFA in which it was distinct from the other two types of stressors with a CFA in which different combinations of two latent factors represented two types of stressors. We also compared the adequacy of the stressors' conceptualizations by examining the CFA of a single factor of stressors representing all three types of stressors in the study. We found clear superiority for our hypothesized three unique types of stressors, role stressors, critical job events, and work-related hassles. (For the full set of results of the set of confirmatory factor analyses conducted, please write to the first author.) In Figure 2, we provide the full details of the factor weights of each latent variable's indicators at T1 and T2 (this information is not repeated in Figure 3). We found strong evidence supporting the factorial invariance of all latent factors across $\mathrm{T} 1$ and $\mathrm{T} 2$. We also found that the assessed measurement models were highly acceptable. For example, the $\mathrm{T} 1$ measurement model had $\chi 2=156, \mathrm{df}=95, \mathrm{TLI}=.94, \mathrm{CFI}=.95$, RMSEA $=.05(\mathrm{CI}=.04$ -.07 ), and SRMR $=.05$. In sum, we found that the goodness of approximate fit of each latent variable at T1 and $\mathrm{T} 2$, as well as of the entire measurement model, was highly acceptable (further details are available from the authors upon request).

\section{Results}

The intercorrelations, means, and standard deviations for each variable included in our model are presented in Table 1. All stressor measures showed a significant increase in the levels of stressors between Time 1 and Time 2 (see the three underlined means, last column, Table 1). This provided strong support to our theoretical assumption about the changing meaning of stressors across time for novice nurses. Table 1 also presents the correlation matrix between Time 1 and Time 2 measures. Below we provide the results of the specific major 
hypotheses formulated above.

Before testing the specific hypotheses, we examined the overall fit of the model as described in Figure 1. The results of testing the full structural model appear in Table 2, under F. As is evident from Table 2, in terms of overall model fit, clearly the hypothesized model or full structural model, Model F, fits the data better than the alternative models, Models D and E, also based on T2 while controlling for T1 variables. The two alternative models, Models D and E, are nested within Model F.

$\mathrm{T} 2$ critical job events predict T2 work-related hassles (Hypothesis 1) and T2 critical job events predict T2 distress (Hypothesis 2). As evident from Figure 2, there is strong support for both hypotheses. The paths from T2 critical job events to T2 work-related hassles were both found to be significant $(\beta=.29$ and .17 , respectively; $\mathrm{p}<.05)$.

T2 work-related hassles predict T2 role stressors (Hypothesis 3) and T2 role stressors predict T2 Distress (Hypothesis 4). We found strong support for these two hypotheses, with the paths from T2 work-related hassles to T2 role stressors and from T2 role stressors to T2 distress both significant, as depicted in Figure $2(\beta=.42$ and .25 , respectively; $\mathrm{p}<.05$ ).

Alternative models. In our study, we also tested several alternative models.

We tested the alternative models based on our $\mathrm{T} 2$ wave of measurement and after controlling for the effects of $\mathrm{T} 1$ variables on their corresponding T2 levels. In addition, we also examined if we could replicate our hypotheses based on the T1 measurements only. These additional tests had the advantage of making the findings of our study directly comparable to past research, which is largely cross-sectional.

The frequently used sequential approach to testing mediation, as proposed by Baron and Kenny (1986), was shown by MacKinnon (2008) to have serious limitations. Therefore, we tested the statistical significance of the two mediation effects depicted in Figure 2 and described above as alternative models by using the method suggested by MacKinnon and Fairchild (2009). Using this method, we found that both mediation effects were statistically significant (for $\mathrm{T} 1, \mathrm{Z}=2.08$; for $\mathrm{T} 2, \mathrm{Z}=2.73$; for both, $\mathrm{p}<.05$ ). These results provide support for the mediation hypothesis.

Table 1. Intercorrelations, reliabilities, means, and standard deviations of all study variables

\begin{tabular}{|c|c|c|c|c|c|c|c|c|c|c|c|c|c|}
\hline Variable & 1 & 2 & 3 & 4 & 5 & 6 & 7 & 8 & 9 & 10 & 11 & Mean & SD. \\
\hline 1.Number of children, $\mathrm{T} 1$ & - & & & & & & & & & & & .70 & 1.13 \\
\hline 2.Age, $\mathrm{T} 1$ & $.74 *$ & - & & & & & & & & & & 27.5 & 5.73 \\
\hline 3.Challenge (Hardiness), & -.03 & .02 & - & & & & & & & & & 1.63 & .33 \\
\hline 4.Critical job events, $\mathrm{T} 1$ & $-.19 *$ & -.14 & .01 & - & & & & & & & & 2.84 & 2.43 \\
\hline 5.Hassles, T1 & -.09 & $-.19 *$ & -.10 & $.27 *$ & - & & & & & & & 1.87 & .57 \\
\hline 6.Role stressors, $\mathrm{T} 1$ & .05 & .02 & $-.15^{*}$ & .06 & $.42 *$ & - & & & & & & 1.94 & .50 \\
\hline 7.Distress, $\mathrm{T} 1$ & -.11 & -.07 & $-.26^{*}$ & .20 & $.18^{*}$ & $.30^{*}$ & - & & & & & 2.56 & .69 \\
\hline 8.Critical evens, $\mathrm{T} 2$ & $-.20^{*}$ & $-.21^{*}$ & -.10 & $.47 *$ & $.30^{*}$ & $.20^{*}$ & $.20^{*}$ & - & & & & 3.39 & 2.60 \\
\hline 9.Hassles, T2 & $-.17 *$ & $-.20 *$ & -.12 & $.18^{*}$ & $.67^{*}$ & $.36^{*}$ & $.24 *$ & $.41^{*}$ & - & & & 1.95 & .55 \\
\hline 10.Role Stressors, T2 & -.04 & -.03 & $-.14^{*}$ & .06 & $.31^{*}$ & $.65^{*}$ & $.37 *$ & $.26^{*}$ & $.45^{*}$ & - & & 2.00 & .50 \\
\hline 11.Distress, T2 & $-.20 *$ & $-.24 *$ & $-.25^{*}$ & $.33 *$ & $.18^{*}$ & $.22 *$ & $.63 *$ & $.34 *$ & $.27 *$ & $.42 *$ & - & 2.57 & .71 \\
\hline
\end{tabular}

Note. $\mathrm{N}=191$. Starred coefficients are significant at the $\mathrm{p}<.05$ level. An underlined mean indicates that it was found to be significantly different from its $\mathrm{T} 1 \mathrm{level}$, using a T-test $(\mathrm{p}<.05)$. 
Table 2. Indices of approximate fit with the data and for the structural models compared

\begin{tabular}{|c|c|c|c|c|c|c|c|c|c|c|}
\hline Model & $\chi^{2}$ & df & TLI & CFI & RMSEA & $\begin{array}{l}\text { RMSEA } \\
(90 \% \text { C.I.) }\end{array}$ & SRMR & $\begin{array}{l}\text { Models } \\
\text { compared }\end{array}$ & $\Delta_{\mathrm{df}}$ & $\begin{array}{l}\text { Sig. } \\
\text { difference }\end{array}$ \\
\hline
\end{tabular}

Model A: T1 Role stressors as fully mediating the effects of T1 critical job events and T1 work-related hassles on T1 distress

$$
\begin{array}{lllllllllllll}
318 & 218 & .94 & .95 & .050 & (.057-.061) & .081 & \text { A vs. B } & 9 & 4 & \text { n.s. }
\end{array}
$$

Model B: T1 Role stressors as partially mediating the effects of both T1 critical job events and T1 hassles on T1 distress

$$
\begin{array}{lllllllllll}
309 & 214 & .94 & .95 & .048 & (.035-.053) & .075 & \mathrm{C} \text { vs. B } & 7 & 2 & \mathrm{p}<.05
\end{array}
$$

Model C: T1 Role stressors as partially mediating the effects of only T1 critical job events on T1 distress

$$
\begin{array}{llllllllllll}
302 & 216 & .95 & .95 & .046 & (.033-.058) & 0.70 & \text { C vs. A } & 16 & 2 & \mathrm{p}<.01
\end{array}
$$

2. The Hypothesized Model, Model F, Compared with alternative models based on T2 (T1 controlled)

D - Model C and arrows a + b, Figure 1; An alternative model to the hypothesized model (F)

$$
\begin{array}{lllllllllll}
292 & 214 & .95 & .96 & .045 & (.031-.057) & .072 & \text { F vs. D } & 14 & 2 & \text { p }<.01
\end{array}
$$

E - Model C and arrows c + d, Figure 1; An alternative model to the hypothesized model (F)

$$
\begin{array}{lllllllllllll}
287 & 214 & .96 & .96 & 043 & (.029-.055) & .067 & \text { F vs. E } & 9 & 2 & \text { p }<.05
\end{array}
$$

F - Model C and arrows $\mathrm{a}+\mathrm{b}+\mathrm{c}+\mathrm{d}$, Figure 1; The Hypothesized Model (reflecting Hypotheses 1 to 4)

$$
\begin{array}{llllll}
278 & 212 & .96 & .97 & .041 & (.028-.053) \quad .065
\end{array}
$$

Note: $\mathrm{N}=188 . \quad \chi^{2}=$ chi-square, given in whole numbers; d.f. $=$ degrees of freedom; TLI = Tucker-Lewis index; $\mathrm{CFI}=$ comparative fit index; RMSEA = root mean square error of approximation; $\mathrm{CI}=$ confidence in level; $\mathrm{SRMR}=$ standardized root mean square resident. $\Delta \chi^{2}=$ refers to the change in $\chi^{2}$ between the first and the second models as they appear in the column headed "models compared".

Time 1

Time 2
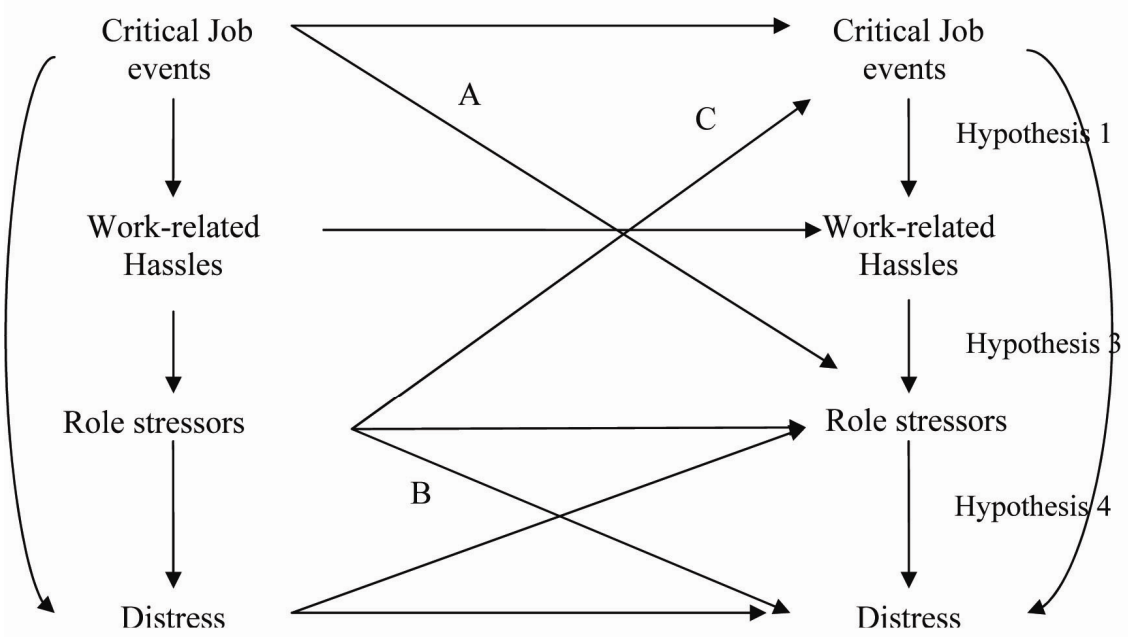

Hypothesis 2

Figure 1. The theoretical model: Predicting the contemporaneous and diarole effects of work-related critical job events, hassles, and role stressors on distress 


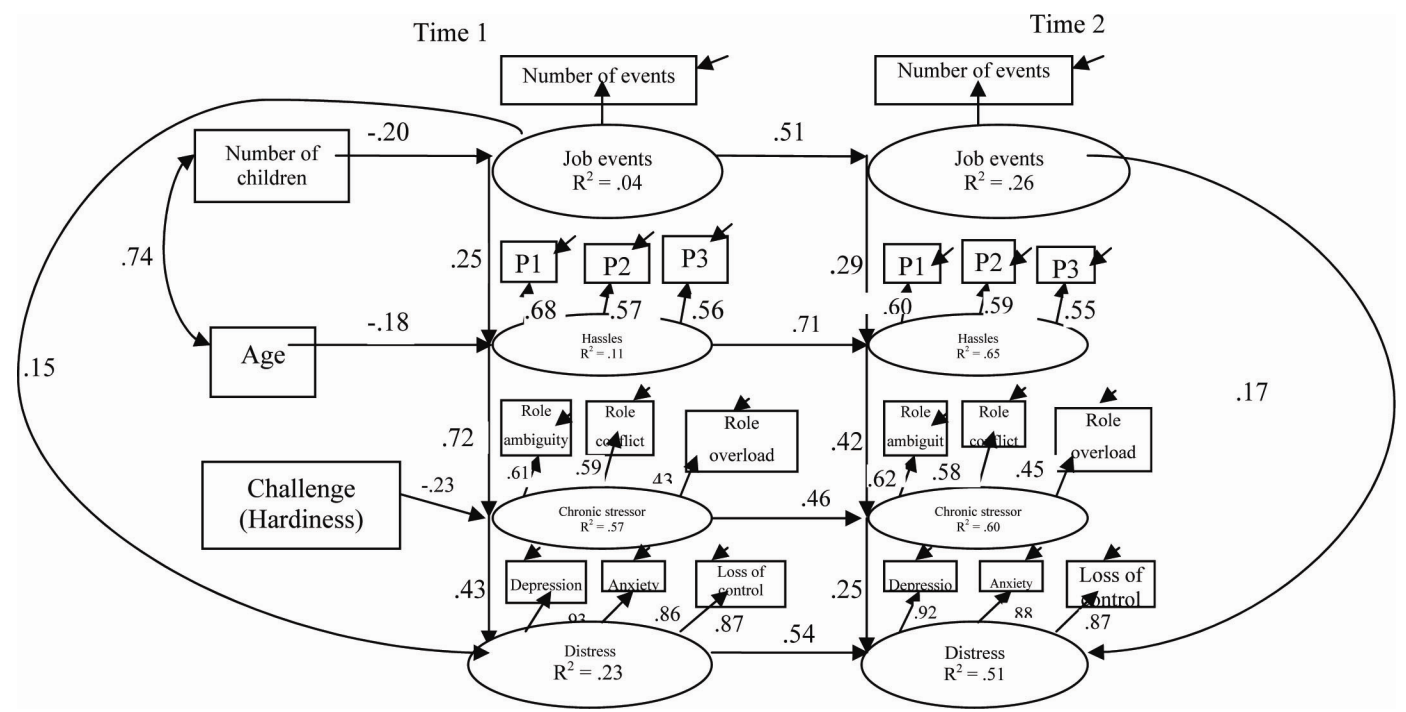

Figure 2. Role stressors as fully mediating the contemporaneous effects of hassles $\mathrm{n}$ distress and partially mediating the effects of critical job events on distress (Model C)

Note. All figures represent standardized coefficients. Solid lines and curves represent statistically significant hypothesized paths or correlations at $\mathrm{p}<.05$. Broken lines represent insignificant hypothesized paths. T1 and T2 represent data collected at Time 1 and Time 2, respectively. For single-headed arrows, the standardized regression coefficients are represented. For the curved, double-headed arrow, the correlation is presented. To simplify the presentation, the correlations among the error terms of the same indicators across time are not shown. Job events refer to critical job events.

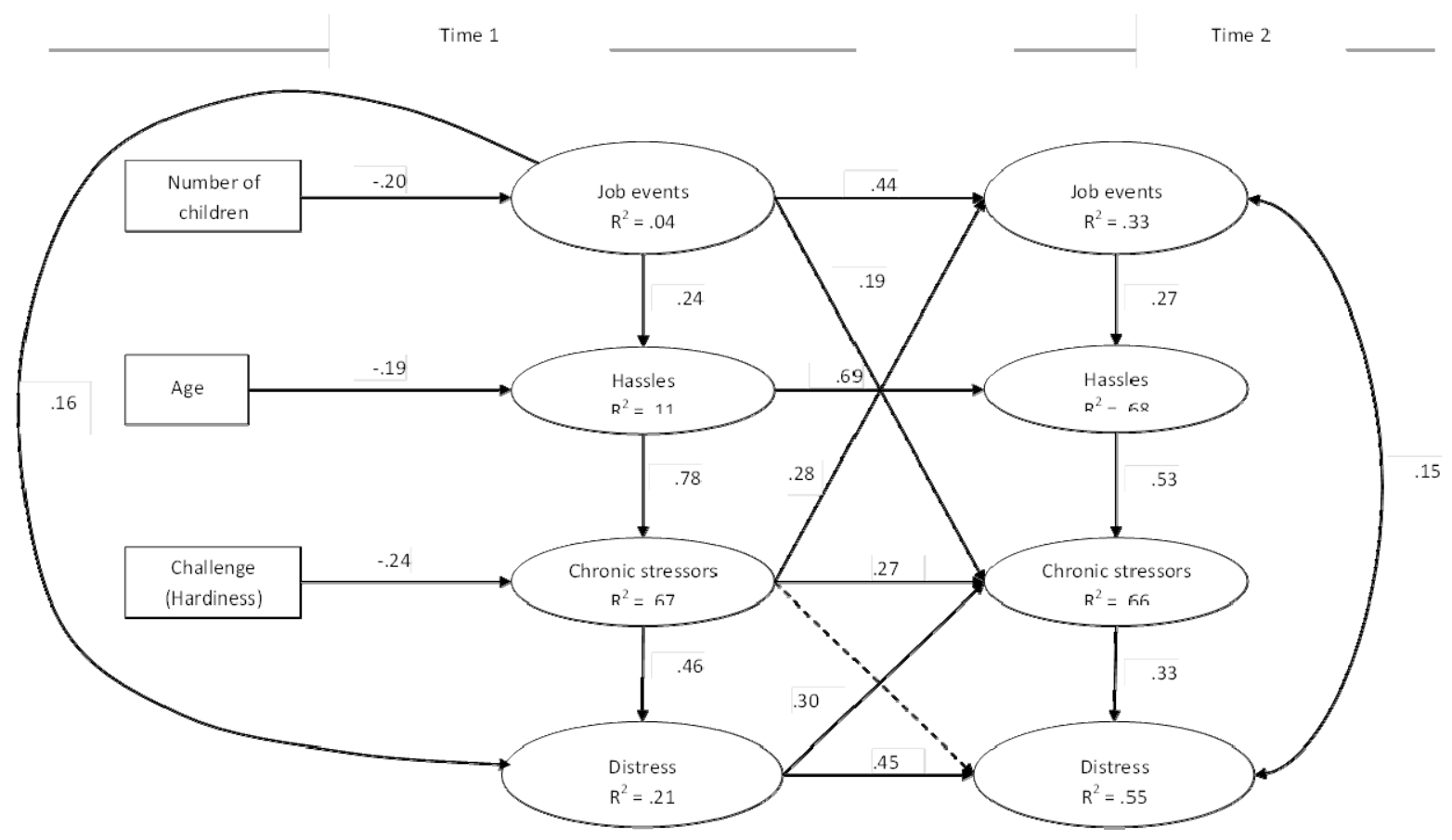

Figure 3. Testing the theoretical model: The contemporaneous and diarole effects of work-related critical job events, hassles, and role stressors on distress

Note. All figures represent standardized coefficients. Solid lines and curves represent statistically significant hypothesized paths or correlations at $\mathrm{p}<.05$. Broken lines represent insignificant hypothesized paths. T1 and T2 represent data collected at Time 1 and Time 2, respectively. For single-headed arrows, the standardized regression coefficients are represented. For the curved, double-headed arrow, the correlation is presented. To simplify the presentation, the correlations among the error terms of the same indicators across time are not 
shown. Job events refer to critical job events.

\subsection{Other Findings}

Because all the hypotheses are based on T2 after controlling for T1 waves of measurement, we could test all our hypotheses based on a comparison of the overall fit of a model based on T1 only versus the full model described in Figure 2. Therefore, we could use the $\chi^{2}$ difference test to compare the best fitting T1 model, Model C, with the best fitting T2-based model, Model F, reflecting our set of hypotheses. We found that the difference between them was significant $\left(\Delta \chi^{2}=24, \Delta\right.$ d.f. $\left.=4, \mathrm{p}<.0001\right)$, suggesting that the best-fitting model representing all the hypotheses added to the goodness of fit of the tested model with the data relative to the T1 only alternative model. In terms of explaining the variance of $\mathrm{T} 2$ distress, Model $\mathrm{F}$ improved on it significantly $(\triangle \mathrm{R} 2=.04, \mathrm{p}$ $<.05)$.

\section{Discussion}

Although T1-T2 changes in critical job events and role stressors each made a unique contribution to the prediction of T1-T2 changes in distress, the effects of T1-T2 changes in hassles on changes in the levels of distress were fully mediated by $\mathrm{T} 2$ role stressors. We were able to fully replicate this set of findings for the $\mathrm{T} 1$ only set of relationships among the three types of stressors and distress. Our hypotheses were tested on a relatively homogeneous sample of new graduate nurses (almost all females) at their initial stages of work in hospitals. Overall, our results highlight the (expected) importance of changes across time in role stressors, as predictors of changes in the levels of distress and, by implication, mental health.

Our findings suggest that the system of variables under study lack stability when the term is defined as constancy of means across time (Cole \& Maxwell, 2003, p. 560). In order to determine whether the causal structure examined in the current study is stationary, characterized by temporal stability in the patterns of the variables' covariance, it is necessary to compare three or more waves of measurement. At T2, each variable represents the change in its level from T1; therefore, the mediation effect that we found in $\mathrm{T} 1$ represents constructive replication of the same effect expected by us for $\mathrm{T} 2$ controlling for $\mathrm{T} 1$.

The present design had several distinct advantages. First, the relatively high response rate obtained in the study adds a degree of meaningful external validity to the specific population that was sampled. Second, three different types of stressors were measured simultaneously and were examined at two separate times, using a longitudinal design. Third, the scales assessing the three types of stressors were carefully devised to avoid confounding items. Some past studies of pairs of stressors were criticized for using confounded measures (Almeida \& Kessler, 1998), which may also explain the contradictory results. Fourth, we attempted to enhance the study's internal validity by applying a variety of techniques. The longitudinal data were measured at meaningfully spaced intervals, starting from the time nurses entered their new, mostly first, hospital job and about six months later. Past studies found it difficult to determine the direction of causality between role stressors and distress or depression, because of the indeterminate timing of role stressors and depressive symptoms (Hammen, 2005). Thus, the design of our longitudinal study lends credibility to the claim that the direction is from role stressors to distress. Data were analyzed using SEM, an analytic technique that reduces the possible biasing influence of unreliability of multiple-item variables. Among other advantages, our use of instrumental variables in the SEM analysis controlled for several possible confounders, such as age.

This study had several limitations. The external validity of the findings in occupations other than nursing needs to be established in future research. Because the participants were young females in their reproductive years, this implies that important stressors in their lives, such as parent-related homework conflicts, were ignored. It is possible that because we did not assess stressors in domains other than work, we underestimated the effects of stressors on distress. Additionally, about $25 \%$ of our sample consisted of nurses who were new employees in the current hospital when they responded to our questionnaires, but had already worked in hospital nursing elsewhere. We used age as an instrumental variable in testing our models. The above subgroup of nurses was on average significantly older than the $75 \%$ of the sample that consisted of novice nurses. Therefore, we probably controlled for a major characteristic of this subgroup of nurses with prior experience in the profession. We recommend that future research investigate the possibility that there are differences in the three types of stressors among different subgroups of nurses newly employed in a hospital. In the current study, the number of newly recruited nurses who were previously employed by other hospitals, but moved, was too small to allow this detailed analyses. We also recommend that future research use randomized coefficients modeling (RCM) to model the nested nature of the data - nurses within hospitals. In the current study, this was not possible because for many participants there were only a few nurses available for analysis at the level of the participating hospital 
(sometimes only one or two per hospital). To allow RCM, future researchers need to sample a minimum of 50 cases from each hospital (Klein \& Kozlowski, 2000; Haas \& Hox, 2005).

Our sample consisted of nurses in the early stage of their careers, not yet moving on to nursing jobs requiring higher levels of responsibility. Therefore, future research should replicate our findings using samples of experienced nurses. Future studies may also examine the possibility that there is a need to increase the time lag among waves of measurement to capture processes which take more time to develop and mature, for example erosion of coping resources by role stressors. There is some evidence supporting this conjecture in a study of role stressors and changes in distress across time (Lepore, Evans, \& Schneider, 1991).

Our findings have some implications for human resources practitioners. The results suggest that role stressors represent a crucially important link between different types of stressors and employees' levels of distress. In contrast to critical job events and work-related hassles, it is difficult to know how and when most role stressors will be resolved. Therefore, we suggest that interventions directed at ameliorating role stressors or buttressing employees' coping skills might beneficially affect their psychological well-being. To be optimally effective, planned interventions might be constructed to affect all the role stressors examined here. Based on the study findings, we would like to suggest additional practitioner-oriented recommendations. As a general shortage of nurses is a public health problem in many countries, retention of currently available nursing staff has become a major challenge to employers. Turnover has been associated with several types of antecedents, including negative affectivity and distress, job alternatives, ease of leaving, job attitudes (especially job satisfaction and commitment), and push factors such as role stressors, hassles and critical job events (Griffeth, Hom, \& Gaertner, 2000; Zimmerman, 2008). Our study suggests that to reduce the risk of push factors such as those above from leading to turnover decision on the part of nurses, it would be a prudent and efficient human resource practice to try to contain and reduce role stressors, including role ambiguity, role conflict, and workload. As noted, these push factors are likely to be key mediators of the effects of hassles and critical job-related events on their levels of distress.

Future research may examine alternative theoretical models other than those actually tested in the current study. For example, we did not test the possibility that the different types of stressors interact in impacting distress, primarily because most studies that examined this possibility for different pairs of the stressors under study, failed to find support for the existence of such a moderating effect (for supporting evidence, see: Chamberlain $\&$ Zika, 1990; Kanner, Coyne, Schaefer, \& Lazarus, 1981; Monroe, 1983; Pillow, Zautra, \& Sandler, 1996). However, interactive effects were found in one study (Serido, Almeida, \& Wethington, 2004), and therefore, need to be tested in future research. We considered the possibility of adding interactions to the hypothesized model. We decided not to follow this route because Kline (2011), following a description proposed in the SEM literature of six different ways to construct interactions among predictors in SEM models, reached the conclusion that as yet there is no one best way for this purpose. Types of stressors not considered here could be added to the theoretical models, such as stressors occurring in other life domains or traumas. Individuals vary in their propensity to report distress (Hammen, 2005). Therefore, future research may find it worthwhile to examine the possibility that certain personality factors, such as neuroticism, moderate stressor-distress relationships. Because our sample consisted mostly of females, we could not assess gender differences in the relationships examined in the current study, a possibility suggested by earlier research (Almeida \& Kessler, 1998). Similarly, future research may test our theoretical model for older or more senior employees than those included in the sample.

This study facilitates the development of more complex models, incorporating different types of stressors as they impact psychological functioning. For example, additional types of stressors, such as traumatic events, could be easily added to our model. Also, examining other moderators, including perceptions of work-related control, available and utilized social support, the predictability of each type of stressors, and the often analyzed distinction between problem-focused versus emotion-focused coping patterns may provide further insight into the effects of stressors on mental health.

\section{References}

Aldwin, C. M. (2007). Stress, coping, and development: An integrative perspective (2nd ed.). New York City, N.Y., USA: Guilford Press.

Almeida, D. M., \& Kessler, R. C. (1998). Everyday stressors and gender differences in daily distress. Journal of Personality and Social Psychology, 75(4), 670-680. http://dx.doi.org/10.1037/0022-3514.75.3.670

Antonakis, J., Bendahan, S., Jacquart, P., \& Lalive, R. (2010). On making causal claims: A review and $\begin{array}{llll}\text { recommendations. The Leadership } & \text { Quarterly, } & \text { 21(6), }\end{array}$ http://dx.doi.org/10.1016/j.leaqua.2010.10.010 
Baron, R. M., \& Kenny, D. A. (1986). The moderator-mediator variable distinction in social psychological research: Conceptual, strategic, and statistical considerations. Journal of Personality and Social Psychology, 51, 1173-1182. http://dx.doi.org/10.1037/0022-3514.51.6.1173

Baruch, Y., \& Holtom, B. C. (2008). Survey response rate levels and trends in organizational research. Human Relations, 61(8), 1139-1160. http://dx.doi.org/10.1177/0018726708094863

Brough, P. (2004). Comparing the influence of traumatic and organizational stressors on the psychological health of police, fire, and ambulance officers. International Journal of Stress Management, 11(3), 227-244 http://dx.doi.org/10.1037/1072-5245.11.3.227

Chamberlain, K., \& Zika, S. (1990). The minor events approach to stress: Support for the use of daily hassles. British Journal of Psychology, 81(4), 469-481. http://dx.doi.org/10.1111/j.2044-8295.1990.tb02373.x

Church, A. H. (1993). Estimating the effect of incentives on mail survey response rates: A meta-analysis. Public Opinion Quarterly, 57(1), 62-79. http://dx.doi.org/10.1086/269355

Cole, D. A., \& Maxwell, S. E. (2003). Testing mediational models with longitudinal data: Questions and tips in the use of structural equation modeling. Journal of Abnormal Psychology, 112(4), 558-577. http://dx.doi.org/10.1037/0021-843X.112.4.558

Crandall, C. S. (1992). Psychophysical scaling of stressful life events. Psychological Science, 3(4), 256-258. http://dx.doi.org/10.1111/j.1467-9280.1992.tb00039.x

Dohrenwend, B. P. (2006). Inventorying stressful life events as risk factors for psychopathology: Toward resolution of the problem of intracategory variability. Psychological Bulletin, 132(3), 477-495. http://dx.doi.org/10.1037/0033-2909.132.3.477

Eckenrode, J. (1984). Impact of role and acute stressors on daily reports of mood. Journal of Personality and Social Psychology, 46(4), 907-918. http://dx.doi.org/10.1037/0022-3514.46.4.907

Florian, V., \& Drory, Y. (1990). Mental Health Inventory (MHI): Psychometric properties and normative data in the Israeli population. Psychologia: Israel Journal of Psychology, 2(1), 26-35.

Folkman, S. (1984). Personnel control and stress and coping processes: A theoretical analysis. Journal of Personality \& Social Psychology, 46(4), 839-852. http://dx.doi.org/10.1037/0022-3514.46.4.839

Foster, E. M., \& McLanahan, S. (1996). An illustration of the use of instrumental variables: Do neighborhood conditions affect a young person's chance of finishing high school? Psychological Methods, 1(3), 249-260.

Gilboa, S., Shirom, A., Fried, Y., \& Cooper, C. L. (2008). A meta-analysis of work demand stressors and job performance: Examining main and moderating effects. Personnel Psychology, 61(2), 227-271. http://dx.doi.org/10.1111/j.1744-6570.2008.00113.x

Glickman, L., Tanaka, J. S., \& Chan, E. (1991). Life events, role strain, and psychological distress: Longitudinal causal models. Journal of Community Psychology, 19(4), 283-305. http://dx.doi.org/10.1002/1520-6629(199110)19:4<283::AID-JCOP2290190402>3.0.CO;2-5

Gray-Toft, P., \& Anderson, J. G. (1981). The nursing stress scale: Development of an instrument. Journal of Psychopathology and Behavioral Assessment, 3(1), 11-23. http://dx.doi.org/10.1007/BF01321348

Hammen, C. (2005). Stress and depression. Annual Review of Clinical Psychology, 1, 293-319. $\mathrm{http}: / / \mathrm{dx}$. doi.org/10.1146/annurev.clinpsy.1.102803.143938

Hart, P. M., \& Cooper, C. L. (2002). Occupational stress: Toward a more integrated framework (Vol. 2). London, U. K.: Sage Publications.

Heim, C., \& Nemeroff, C. B. (2001). The role of childhood trauma in the neurobiology of mood and anxiety disorders: Preclinical and clinical studies. Biological Psychiatry, 49(12), 1023-1039. http://dx.doi.org/10.1016/S00063223(01)01157-X

Holahan, C. J., Moos, R. H., Holahan, C. K., Brennan, P. L., \& Schutte, K. K. (2005). Stress generation, avoidance coping, and depressive symptoms: A 10-year model. Journal of Consulting and Clinical Psychology, 73(4), 658-666. http://dx.doi.org/10.1037/0022-006X.73.4.658

Kanner, A. D., Coyne, J. C., Schaefer, C., \& Lazarus, R. S. (1981). Comparison of two models of stress measurement: Daily hassles and uplifts versus major life events. Journal of Behavioral Medicine, 4(1), 1-9. http://dx.doi.org/10.1007/BF00844845

Klein, K. J., \& Kozlowski, S. W. J. (2000). From micro to meso: Critical steps in conceptualizing and conducting 
multilevel research. Organizational Research Methods, 3(3), 211-236. http://dx.doi.org/10.1177/109442810033001

Kline, R. B. (2011). Principles and practice of structural equation modeling (3rd ed.). New York City, N.Y., USA: The Guilford Press.

Kobasa, S. C., \& Pucetti, M. C. (1983). Personality and social resources in stress resistance. Journal of Personality and Social Psychology, 45, 839-850. http://dx.doi.org/10.1037/0022-3514.45.4.839

Koslowsky, M. (1998). Modeling the stress-strain relationship in work settings. London, U.K.: Routledge. http://dx.doi.org/10.4324/9780203277591

Kravetz, S., Drory, Y., \& Florian, V. (1993). Hardiness and sense of coherence and their relation to negative affect. European Journal of Personality, 7(4), 233-244. http://dx.doi.org/10.1002/per.2410070404

Lazarus, R. S., \& Folkman, S. (1984). Stress, appraisal, and coping. New York: New York: Springer.

Lepore, S. J., \& Evans, G. W. (1996). Coping with multiple stressors in the environment. In M. Zeidner, \& N. Endler (Eds.), Handbook of coping: Theory, research, and applications (pp. 350-377). New York, New York: Wiley \& Sons.

Lepore, S. J., Evans, G. W., \& Schneider, M. L. (1991). Dynamic role of social support in the link between role stress and psychological distress. Journal of Personality and Social Psychology, 61(6), 899-909. http://dx.doi.org/10.1037/0022-3514.61.6.899

Levav, I., Krasnoff, L., \& Dohrenwend, B. S. (1981). Israeli PERI life event scale: Ratings of events by a community sample. Israel Journal of Medical Sciences, 17(2-3), 176-183.

Little, T. D., Cunningham, W. A., Shahar, G., \& Widaman, K. F. (2002). To parcel or not to parcel: Exploring the question, weighing the merits. Structural Equation Modeling, 9(2), 151-173. http://dx.doi.org/10.1207/S15328007SEM0902_1

MacKinnon, D. P. (2008). Introduction to statistical mediation analysis. New York City, NY, USA: Erlbaum Associates.

MacKinnon, D. P., \& Fairchild, A. J. (2009). Current directions in mediation analysis. Current Directions in Psychological Science, 18(1), 16-20. http://dx.doi.org/10.1111/j.1467-8721.2009.01598.x

Monroe, S. M. (1983). Major and minor life events as predictors of psychological distress: Further issues and findings. Journal of Behavioral Medicine, 6(2), 189-205.

Monroe, S. M., \& Harkness, K. L. (2005). Life stress, the "Kindling" hypothesis, and the recurrence of depression: Considerations from a life stress perspective. Psychological Review, 112(2), 417-445. http://dx.doi.org/10.1007/BF00845380

Monroe, S. M., Slavich, G. M., Torres, L. D., \& Gotlib, I. H. (2007). Major life events and major chronic difficulties are differentially associated with history of major depressive episodes. Journal of Abnormal Psychology, 116(1), 116-124. http://dx.doi.org/10.1037/0021-843X.116.1.116

Neupert, S. D., Almeida, D. M., \& Charles, S. T. (2007). Age differences in reactivity to daily stressors: The role of personal control. The Journals of Gerontology Series B: Psychological Sciences and Social Sciences, 62(4), 216-225.

O'Boyle, E. H., Jr., \& Williams, L. J. (2011). Decomposing model fit: Measurement vs. theory in organizational research using latent variables. Journal of Applied Psychology, 96(1), 1-12.

Ortqvist, D., \& Wincent, J. (2006). Prominent consequences of role stress: A meta-analytic review. International Journal of Stress Management, 13(4), 399-422. http://dx.doi.org/10.1037/1072-5245.13.4.399

Pillow, D. R., Zautra, A. J., \& Sandler, I. (1996). Major life events and minor stressors: Identifying mediational links in the stress process. Journal of Personality and Social Psychology, 70(2), 381-394. http://dx.doi.org/10.1037/0022-3514.70.2.381

Rizzo, J. R., House, R. J., \& Lirtzman, S. I. (1970). Role conflict and ambiguity in complex organizations. Administrative Science Quarterly, 15, 150-163. http://dx.doi.org/10.2307/2391486

Saks, A. M., \& Ashforth, B. E. (2000). The role of dispositions, entry stressors, and behavioral plasticity theory in redicting newcomers' adjustment to work. Journal of Organizational Behavior, 21(1), 43-62. http://dx.doi.org/10.1002/(SICI)1099-1379(200002)21:1<43::AID-JOB985>3.0.CO;2-W 
Serido, J., Almeida, D. M., \& Wethington, E. (2004). Role stressors and daily hassles: Unique and interactive relationships with psychological distress. Journal of Health and Social Behavior, 45(1), 17-33. http://dx.doi.org/10.1177/002214650404500102

Shirom, A., Shechter-Gilboa, S., Fried, Y., \& Cooper, C. L. (2008). Gender, age and tenure as moderators of work-lated stressors' relationships with job performance: A meta-analysis. Human Relations, 61(10), 1371-1398. http://dx.doi.org/10.1177/0018726708095708

Van Eck, M., Nicolson, N. A., \& Berkhof, J. (1998). Effects of stressful daily events on mood states: Relationship to global perceived stress. Journal of Personality and Social Psychology, 75(6), 1572-1585. http://dx.doi.org/10.1037/0022-3514.75.6.1572

Veit, C. T., \& Ware, J. E. (1983). The structure of psychological distress and well-being in general populations. Journal of Consulting and Clinical Psychology, 51(5), 730-742.

Wagner, B. M. (1990). Major and daily stress and psychopathology: On the adequacy of the definitions and methods. Stress Medicine, 6(3), 217-226. http://dx.doi.org/10.1002/smi.2460060307

Wheaton, B. (1994). Sampling the stress universe. New York, NY, USA: Plenum Press.

Wheaton, B. (1997). The nature of role stress. In B. H. Gottlieb (Ed.), Coping with role stress (pp. 43-73). New York, NY: Plenum Press.

Williams, L. J., \& O'Boyle, E. H. (2008). Measurement models for linking latent variables and indicators: A reviewof human resource management research using parcels. Human Resource Management Review, 18(4), 233-242. http://dx.doi.org/10.1016/j.hrmr.2008.07.002

\section{Copyrights}

Copyright for this article is retained by the author(s), with first publication rights granted to the journal.

This is an open-access article distributed under the terms and conditions of the Creative Commons Attribution license (http://creativecommons.org/licenses/by/3.0/). 